Inmaculada Donaire del Yerro

Universidad Autónoma de Madrid

\title{
EL GRAN TEATRO DE VETUSTA
}

\section{Introducción}

El presente trabajo pretende llevar a cabo una inmersión en la realidad novelesca de La Regenta. Accederemos desde el epicentro mismo del relato, el capítulo XVI, en el que se concentra todo el asunto de la novela ${ }^{1}$. Clarín destacó este capítulo como «uno de los principales para la acción interna del libro» ${ }^{2}$. Y su ubicación central, sirviendo de gozne entre la primera y la segunda parte de este fragmento de vida de los vetustenses, así parece indicarlo. Tal ubicación junto con la estructura de los distintos planos de la realidad, para nosotros ficcional, dentro del propio capítulo XVI evoca la imagen de un juego de muñecas rusas. Aunque, como veremos más adelante, la complejidad del universo vetustense, como estudio mimético ${ }^{3}$ que es de la realidad extraliteraria, no puede constreñirse en un solo esquema estructural estático. Al contrario, Clarín dota a esta realidad de un dinamismo vital con el que hace patente el estancamiento de Vetusta.

La concepción de la novela como estudio, retrato de una realidad, y lo que creo más arriesgado, de la realidad contemporánea del escritor, es la que ha guiado este trabajo. Creo que es a través del artificio literario como Clarín consigue crear la perspectiva histórica necesaria para llevar a cabo ese estudio de la realidad, actual para él y sus contemporáneos. De ahí que sean las herramientas propias del escritor el punto de partida que propongo para una lectura crítica de este fragmento tan histórico como atemporal.

\section{Estructura pendular y tiempo circular}

Mi caracterización de la estructura del capítulo XVI parte del esquema propuesto por Alarcos ${ }^{4}$ para el conjunto de la obra. Tal esquema sigue la división establecida por el propio Clarín. A los primeros quince capítulos les asigna Alarcos una función presentativa y a los quince restantes una función activa. Basa su esquema en la «desproporción temporal» que encontramos entre una y otra parte: tres días del tiempo narrativo transcurren en los primeros quince capítulos, frente a los tres años que presenciamos en los quince segundos. Para este estudioso existe una clara correspondencia entre esa desproporción temporal y el predominio de lo estático o lo dinámico, lo descriptivo espacial o lo narrativo temporal. De esta forma, a la primera parte estática, espacial, morosa, predominantemente descriptiva, le asigna una función presentativa. Y a la segunda, dinámica, temporal, con un marcado predominio de lo narrativo sobre lo descriptivo, le asigna una función activa.

1 Sobejano, Gonzalo (1985): «La inadaptada (La Regenta, cap. XVI) ».En: El comentario de textos 1. Madrid: Castalia, pp. 126-166.

2 Alas, Leopoldo, tomado de Fuentes, Víctor ed. (1999): La Regenta. Madrid: Akal. Nota 1 del capítulo XVI.

3 Fuentes, Víctor: «Clarín y la novela de la modernidad naturalista». En: el «Estudio preliminar» a su edición citada de La Regenta.

4 Alarcos, Emilio (1979): «La estructura de La Regenta». En: Rico, Francisco (coord.): Historia y crítica de la literatura española, vol. V. Barcelona: Crítica, pp. 578-583. 
Aplicando este esquema al capítulo XVI, podemos diferenciar una primera parte presentativa que se extiende desde el comienzo del capítulo hasta el encuentro entre Ana Ozores y Álvaro Mesía. Y una segunda parte activa en la que la representación de la obra de Zorrilla tiene un importante papel dinamizador.

En la primera parte Clarín nos vuelve a introducir en el ambiente de Vetusta. Si bien es cierto, como señala Alarcos, que las referencias temporales son aquí más precisas que en los quince capítulos precedentes, nos encontramos en el día de Todos los Santos, Vetusta parece haberse estancado en un ciclo temporal que se repite de manera machacona como el doblar de las campanas «todos los años [...] el día de los Santos» (p. 507) que Clarín expresa contundentemente: «Aquel año la tristeza había aparecido a la hora de siempre» (p. 508). Se trata, por tanto, de una temporalidad cíclica, que vuelve allí de donde parte. Tras rememorar el ambiente de Vetusta, el lector de la primera parte de la novela vuelve a bucear en el personaje individual de Ana Ozores. Con su salida al balcón regresa a la calle de Vetusta, para volver de nuevo al sentimiento de Ana Ozores hacia los vetustenses... y así discurre la lectura siguiendo un movimiento de ida y vuelta, del exterior al interior del personaje, de lo colectivo a lo individual, como si nos encontrasémos encaramados al péndulo de un reloj. Creo que esa alternancia entre lo colectivo y lo individual, sobrepuesta al esquema de Alarcos, constituye la clave estructural y semántica del capítulo.

También encontramos fragmentos con una función eminentemente presentativa en la segunda parte, que he considerado activa: la digresión sobre la situación crítica del arte dramático en la España del XIX y la caracterización cronotópica del «Coliseo de la plaza del Pan». Pero en esta lo fundamental es la legitimación del ideal de libertad de Ana Ozores, a partir de su experiencia teatral, y la decisión de la protagonista de hacerlo realidad a través de su aventura amorosa con Mesía. Aunque para ello sean necesarios doce capítulos más.

A la estructura narrativa pendular que oscila entre el exterior y el interior de los personajes, sobre todo, del personaje central, creo que podemos atribuirle una triple función. Por un lado, el retrato de la sociedad vetustense como personaje colectivo no calaría hondo en la conciencia de los lectores si se encontrase desprovisto del efecto humanizador que le aportan los personajes individuales. Clarín demuestra sobradamente en este capítulo que es consciente de la función catártica de la obra dramática y, por extensión, de la obra literaria. Pero para que la catarsis aristotélica sea posible ha de darse una reacción empática en el espectador o el lector. Esta reacción resulta mucho más fácil de inducir mediante personajes individuales que mediante un personaje colectivo. Por otra parte, la concepción de la realidad novelada como una «imitación total y directa del mundo» ${ }^{6} \mathrm{im}$ pone la exigencia de trazar no solo un retrato sociológico, sino también un estudio psicológico de los personajes. Y en último término, y creo que esta es la función más importante de la estructura narrativa propuesta, el vaivén entre el exterior y el interior de los personajes se nos muestra solidario con el tema que vertebra la novela: el de la oposición entre el individuo y su medio, el condicionamiento del sujeto por la norma social y, en última instancia, su alienación. Como ejemplo palmario de tal dominio del individuo por las normas sociales Clarín nos presenta una mujer que, a pesar de constituir el centro de

\footnotetext{
5 Para las citas de La regenta he empleado la edición de Víctor Fuentes (1999). Madrid: Akal.

6 Tomado de: Fuentes, Víctor (1999), ob. cit.
} 
todas las miradas («Ana, acostumbrada muchos años hacía, a la mirada curiosa, insistente y fría del público», p. 529) y el personaje central que da título a la novela, no lo hace con su propio nombre, sino con el del cargo público que desempeñara su marido. En esa oposición entre la sociedad y el individuo se encuentra la clave del «realismo crítico» ${ }^{8}$ clariniano para el que resulta fundamental la existencia de un personaje inadaptado, como califica Sobejano9 a Ana Ozores. La estructura pendular a la que me refiero hace patente la existencia de una lucha dialéctica entre dos partes en conflicto en la que Ana Ozores, con todos los significados que podamos encontrar para el personaje, unas veces será protagonista y otras se verá anulada para convertirse en el campo de batalla. Su inadaptación sirve de base, por tanto, para la crítica de una estructura, no un sistema, sociomoral amenazado «por una transformación social que pretendía hacer tabla rasa de todo ello». ${ }^{10}$

Una tercera característica del entramado textual del capítulo XVI, que también podemos extrapolar a la totalidad de la novela, es la circularidad del pensamiento. En este sentido, la estructura se relaciona con el tiempo subjetivo, no con el tiempo cronológico con el que Alarcos hace corresponder las dos partes de la novela, aunque ambas concepciones temporales sean internas a la trama. Es decir, el capítulo comienza y termina con una referencia al biperspectivismo vetustense. «O el cielo o el suelo, todo no puede ser». (p. 507) -dirá el narrador al comienzo- « ¡Así en la tierra como en el cielo!» (p. 549) -concluirá Petra-. Clarín hace partícipe de este modo al lector de esa sensación de que Vetusta es una ciudad estancada en el interior de un bucle temporal, como diríamos hoy. Solo el narrador y Ana Ozores parecen compartir tal sensación, y con esta idea explícita entramos en Vetusta al comienzo del capítulo:

Con Octubre muere en Vetusta el buen tiempo. Al mediar Novienbre suele lucir el sol una semana $[\ldots]$.

Ana Ozores [...]. Todos los años, al oír las campanas doblar tristemente el día de los Santos, por la tarde, sentía una angustia nerviosa que encontraba pábulo en los objetos exteriores, y sobre todo en la perspectiva ideal de un invierno, de otro $^{11}$ invierno, húmedo, monótono, interminable, que empezaba con el clamor de aquellos bronces.

Aquel año la tristeza había aparecido a la hora de siempre. (pp. 507-508)

Nótese cómo la idea de repetición, de hábito, impera en todo el fragmento. El presente del verbo morir no es un presente de actualidad, sino de repetición ${ }^{12}$, como nos indica la cláusula «Con octubre»; la perífrasis aspectual de la oración siguiente no deja lugar a dudas; el doblar de las campanas entraña semánticamente la reiteración que es potenciada por la cláusula inicial «todos los años»; y a continuación, la propia idea de la repetición se reitera en la gradación creciente «otro invierno, húmedo, monótono, interminable», donde el sentido del adjetivo «húmedo» se nos descubre unas líneas más abajo al referirlo a las gotas de lluvia («itan, tan, tan! ¡cuántos! ¡cuántos! ¡y los que faltaban!

\footnotetext{
7 Para las citas del texto he seguido la edición de Fuentes, Víctor (1999). Madrid: Akal.

8 Rodríguez Puértolas (coord.) (1984: 167)

9 Sobejano (1985: 126-166)

${ }^{10}$ Rodríguez Puértolas (1984: 171)

${ }^{11}$ Cursiva del original.

12 Sobejano (1985: 147)
} 
¿qué contaban aquellos tañidos? tal vez las gotas de lluvia que iban a caer en aquel otro invierno»). Y finalmente, una de esas frases de La Regenta que retumban en la conciencia del lector. Y es que hasta las emociones tienen su hora preestablecida en Vetusta.

Tal monotonía, tal estancamiento, tal hastío que crispa los nervios de la Regenta, solo pueden ser entendidos por el lector mediante esa trayectoria narrativa circular en la que la frase final del capítulo nos remite de nuevo al comienzo, en la que la novela comienza y acaba en la catedral, aunque la perspectiva se invierta - no caiga- desde la torre del campanario hasta el suelo de la iglesia.

\section{De las perspectivas al perspectivismo}

Comenzamos la novela mirando Vetusta desde la torre de la catedral, desde el cielo, a través del catalejo del Magistral. Y acabamos nuestra lectura con Ana Ozores, en el suelo; en el suelo de la capilla del Magistral. Una misma realidad desde dos puntos de vista antagónicos entre los que se establece el conflicto. El conflicto de Ana Ozores se encuentra polarizado por dos hombres, «uno diablo y otro santo» (p. 549) dirá Petra; o en palabras de don Benito Pérez Galdós: «el problema de doña Ana Ozores [...] no es otro que discernir si debe perderse por lo clerical o por lo laico.» ${ }^{13}$

El narrador comienza el capítulo XVI con una pequeña digresión acerca del clima en Vetusta. Y así, hablando del tiempo, como si no tuviera nada que decir, nos da una de las claves de lectura de esa dialéctica de contrarios, que no contradictorios. Detengámonos un momento en ese primer párrafo: «Con Octubre muere en Vetusta el buen tiempo» (p. 507). En consonancia con la idea de degradación biológica asociada a la muerte, el narrador nos da una imagen degradada de Vetusta en la que ni el mismo sol se libra del tinte prosaico de la ciudad: «Al mediar Noviembre suele lucir el sol una semana, pero como si fuera ya otro sol, que tiene prisa y hace sus visitas de despedida preocupado con los preparativos del viaje del invierno (p. 507). El brusco contraste entre la elevación denotada por el sol y la cotidianidad de la preocupación que se le atribuye redunda en un efecto humorístico mediante el que el narrador se distancia de manera muy cervantina ${ }^{14}$ de la ciudad y sus habitantes. Tras degradar al astro rey al nivel de los vetustenses, son estos el objeto de tal degradación mediante su animalización: son anfibios. Esta caracterización de los vetustenses trae a la memoria del lector la imagen de uno de los animales más emblemáticos de la fauna que puebla La Regenta: el sapo. Sin embargo, el significado de unos y otro es bien distinto. El sapo de La Regenta viene a ser lo que Carlos Bousoño denomina «símbolo irracional» ${ }^{15}$. El valor semántico de estos «símbolos irracionales», a diferencia del «símbolo tradicional», no puede concretarse en un sustantivo; sino que sugiere en el lector un sentido que puede aventurar, aunque nunca conocerá con cer-

\footnotetext{
${ }^{13}$ Pérez Galdós, Benito (1901): «Prólogo» a la La Regenta. Edición digital de la Biblioteca Virtual Miguel de Cervantes.

${ }^{14}$ El mismo recurso basado en el contraste lo encontramos repetidamente en la voz narradora del «autor de esta verdadera historia» dirigiéndose a don Quijote. Sirva de ejemplo este fragmento del episodio de los leones (II-xvii): «Tú a pie, tú solo, tú intrépido, tú magnánimo, con sola una espada, y no de las del perrillo cortadoras, con un escudo no de muy luciente y limpio acero, [...].» Miguel de Cervantes: El ingenioso hidalgo don Quijote de la mancha. Ed. de Florencio Sevilla Arroyo y Antonio Rey Hazas. Alcalá de Henares: Centro de Estudios Cervantinos, 1994, p. 662.

${ }^{15}$ Bousoño (1970: Cap. X)
} 
teza ${ }^{16}$ su significado. El valor semántico de los «anfibios» puede concretarse en la adaptabilidad de los vetustenses a aquello a lo que «su destino les condena» (p. 507). Mientras que el significado de la imagen del «sapo» en La Regenta resulta mucho menos nítido:

\section{Don Juan, don Juan, yo lo imploro de tu hidalga condición...}

Estos versos, que ha querido hacer ridículos y vulgares, manchándolos con su baba, la necedad prosaica, pasándolos mil y mil veces por sus labios viscosos como vientre de sapo, sonaron en los oídos de Ana aquella noche como frase sublime de un amor inocente. (pp. 543-544)

La voz narradora que expresa aquí lo que Ana Ozores sintió al presenciar el cuarto acto del Tenorio no es la misma voz que llamó «anfibios» a los vetustenses. Aquí no se distancia del personaje. Mira a los vetustenses igualmente a vista de pájaro, pero a través de los ojos de uno de los caracteres a quien presta su voz. El uso del estilo indirecto libre refuerza aquí la oposición de Ana Ozores, la inadaptada, frente a la realidad en la que vive, al equiparar su punto de vista con el del narrador. Ese choque de perspectivas permite a Clarín instaurar una dialéctica de contrarios. Sin embargo, el hecho de que ese narrador empático, camaleónico, preste su voz a los caracteres no nos debe hacer caer en el error de Ana Ozores y del resto de personajes. Para ellos solo existen dos puntos de vista posibles: el suyo y el de los otros. Para Ana, su punto de vista «supra-vetustense» (p.530) frente a la «necedad prosaica» de Vetusta; para Visita, «todo lo que no era parecerse a ella lo llamaba Visita romanticismo» (p. 512). Para el saber popular de Vetusta, «O el cielo o el suelo, todo no puede ser» (p. 507). Esta es la paradoja de esos vetustenses que, aun siendo anfibios, se declaran pertenecientes a uno de los dos grupos mutuamente excluyentes:

Unos protestan todos los años haciéndose de nuevas y diciendo: «iPero ve usted qué tiempo!». Otros, más filósofos, se consuelan pensando que a las muchas lluvias se debe la fertilidad y hemosura del suelo. «O el cielo o el suelo, todo no puede ser.» Ana Ozores no era de los que se resignaban. (p. 507)

«Unos» frente a «otros». La actitud de protesta, de rebeldía, frente a algo tan natural, pero también tan repetitivo, tan monótono y tan irritante subjetivamente como las estaciones lluviosas, se contrapone a la actitud de los que aceptan que la naturaleza y la vida son así, y hay en su aceptación un componente pragmático - «a las muchas lluvias se debe la fertilidad»- y un componente sensualista -«y la hermosura del suelo»-. «O el cielo o el suelo, todo no puede ser». Este refrán condensa en su primera proposición ese biperspectivismo que venimos viendo y en la segunda, la imposibilidad del deseo romántico de la totalidad: «Nada más ridículo en Vetusta que el romanticismo» (p. 513). Respecto al primer significado, el biperspectivismo, reparemos un momento en el contraste con esta otra formulación:

\footnotetext{
${ }^{16}$ Martínez, J. A. (2001): «El punto de vista y las visiones esperpénticas en La Regenta». En: Actas del simposio sobre la obra de Clarín. Praga: Instituto de Estudios Románicos, Universidad Carolina de Praga.
} 
«O el cielo o el suelo».

El cielo o el suelo.

Si nos fijamos en la semántica de ambas expresiones, nos daremos cuenta de que en la primera la repetición de la conjunción delante del primer componente de la coordinación implica que la negación de este supone forzosamente la afirmación del segundo. Mientras que la segunda expresión permite optar por otras posibilidades. La relación de contradicción y no de contrariedad - empleo estos términos con la acepción que les corresponde en el contexto de la semántica basada en la lógica formal ${ }^{17}$ - entre los «unos» y los «otros», entre «el cielo» y «el suelo» se refuerza mediante el cuantificador universal de la expresión esclerecedora del sentido metafórico del refrán vetustense: «Todo no puede ser.» Es decir, esto es todo; «o el cielo o el suelo», no hay otros puntos de vista y, además, no hay opción a la neutralidad. Este es el planteamiento vetustense que se desmorona ante el multiperspectivismo que Clarín hábilmente nos proporciona de manera muy cervantina. Recordemos cómo Cervantes se sirve de los libros de caballerías para darnos una muestra de multiperspectivismo al contrastar las opiniones del cura, el ventero, la ventera, la hija de ambos y Maritornes acerca de ellos (Quijote, I-xxxii, p. 323) ${ }^{18}$. De forma análoga funciona en el capítulo XVI de La Regenta el Don Juan Tenorio de Zorrilla, sobre el que vierten su opiniones tres de los protagonistas: Mesía y don Víctor de forma dialogada y doña Ana a través de uno de los monólogos interiores más reveladores de la novela.

Antes de comentar las tres perspectivas de los personajes de Clarín, reparemos en una diferencia fundamental respecto al fragmento cervantino. Frente al estilo directo empleado por Cervantes en el que el narrador se limita a señalar a quién corresponde cada turno de palabra, Clarín opta por el estilo indirecto en el que siempre tenemos presente la voz del narrador. Este se pone en el lugar del personaje, «pero el que se pone 'en lugar de' es siempre el autor-narrador ${ }^{19}$ y por ese motivo no nos resultan extrañas sus injerencias en el pensamiento de los caracteres. Al comienzo del intercambio de pareceres entre don Álvaro y don Víctor acerca de la obra de Zorrilla, este narrador omnisciente nos pone en antecedentes sobre el pensamiento de Mesía. Y a lo largo de la recreación de la experiencia teatral de la Regenta, no escasean los fragmentos en los que podemos también reconocer a un narrador omnisciente. La impresión inmediata al descubrir esta diferencia es la de que los personajes cervantinos gozan de una libertad que les está vedada a los de Clarín. Esta diferencia me parece definitiva a la hora de entender el condicionamiento del individuo por la sociedad en la que vive hasta llegar al extremo de su alienación.

Si bien los miramos, los puntos de vista de don Víctor y doña Ana no le son ajenos a don Quijote. Don Víctor encuentra indigna de un caballero «la aventura de don Juan con doña Inés» (p. 524), porque don Víctor ve el drama de Zorrilla desde la perspectiva del código del honor de las comedias de capa y espada de nuestro Siglo de Oro. Recordemos que tiene las obras de Calderón sobre la mesa de noche y que tras asistir a la re-

\footnotetext{
${ }^{17}$ Dos proposiciones son contrarias «cuando una excluye lógicamente a la otra [...]. Ahora bien, [...] de la falsedad de una de estas proposiciones no se sigue necesariamente la verdad de la otra». Dos proposiciones [...] son contradictorias «cuando ambas se excluyen mutuamente»; pero, además, alguna de las dos tiene necesariamente que ser verdadera, «ya que en este caso las dos posibilidades agotan todas las opciones posibles.» Escandell Vidal, M. Victoria (2004): Fundamentos de semántica composicional. Barcelona: Ariel, pp. 106-108.

${ }^{18}$ Edición citada.

19 Tacca, Óscar (2000): Las voces de la novela. Madrid: Gredos, p. 79.
} 
presentación de Don Juan, se muestra resuelto a actuar como médico de su honra mediante una «sangría suelta» (p. 546), en caso de que su mujer le faltase.

Doña Ana, por su parte, ve en el drama una representación del amor liberador de la «estrecha regla de hastío y frialdad» en la que ella, como doña Inés, habían profesado, y que sus lecturas piadosas convierten en «locura mística». También doña Ana evoca el teatro calderoniano, aunque no parece ser consciente de ello. Ella no nos remitirá al Calderón de los casos de honra, sino al del drama filosófico, y en concreto, a La vida es sueño (a pesar de haberse negado a asistir a la representación en el capítulo X). Don Álvaro llega a caballo hasta el caserón de los Ozores. La diferencia es que Mesía se muestra como el experto controlador de las formas y las pasiones que es. El propio don Víctor, siempre con el verso pertinente en los labios, nos da la confirmación con su saludo: «Hola, hola, hipogrifo violento/que corriste parejas con el viento» (p. 524). Es precisamente en el palco del teatro donde el narrador nos revela el cambio de perspectiva de Ana: «aquellas bruscas transformaciones del ánimo, las atribuía supersticiosamente a una voluntad superior, que regía la marcha de los sucesos preparándolos, como experto autor de comedias, según convenía al destino de los seres» (p. 529). Hasta este momento había rechazado la idea por parecerle impía: «Parecíale entonces la humanidad compuesto casual que servía de juguete a una divinidad oculta, burlona como un diablo. Pronto volvía la fe [...] a desmoronar aquella torrecilla del orgulloso racionalismo [...]. Se humillaba Ana a los designios de Dios, pero no por esto desaparecía el disgusto de sí misma, ni el valor para seguir la lucha se recobraba...» (p. 515). Para que ese cambio de perspectiva se dé es necesario que Ana se distancie de sí misma, que disponga de otra visión de la realidad: «Desde la aparición de don Álvaro en la plaza, el humor de Ana había cambiado, pasando de la aridez y el hastío negro y frío, a una región de luz y calor que bañaban y penetraban todas las cosas» (p. 529). De igual forma que para Segismundo Rosaura se convierte en su punto de referencia:

Sólo a una mujer amaba;
que fue verdad, creo yo,
en que todo se acabó
y esto sólo no se acaba.
(vv. 2134-2137)

Lo que diferencia a Ana Ozores de Segismundo es que ella se rebela frente al orden establecido y no renuncia a su sentimiento de voluptuosidad, ni perdona a sus tías el haberla encerrado en la prisión de «hastío y frialdad» que es su matrimonio con Quintanar, por miedo a que se cumpliera el destino de perdición con que la habían signado. Qué es esto sino una crítica contra el determinismo. Determinismo basado en una especulación tan falsa como los juicios astrológicos del rey Basilio. Es, precisamente, la concesión que Calderón hace a la mentalidad de su época lo que Clarín elimina en su personaje. Frente al restablecimiento del orden en La vida es sueño, la rebelión de la protagonista en $L a$ Regenta; aunque al final ese orden acabe venciendo al individuo subversivo que piensa «Aquello era caer, sí, pero caer al cielo.» (cap. XXVIII, p. 885).

Dije más arriba que los puntos de vista de don Víctor y doña Ana nos recuerdan al idealista don Quijote. Honra y libertad, respectivamente. ¿Y cuál es el consejo que don

${ }^{20}$ Calderón de la Barca, Pedro (1981): La vida es sueño. José María Valverde (ed.). Barcelona: Planeta. 
Quijote da a Sancho cuando consigue salir del castillo de los duques? «por la libertad, así como por la honra, se puede y debe aventurar la vida» (II-lviii, p. 962) ${ }^{21}$.

Mediante estos dos personajes expone Clarín la vieja y la nueva lectura de Calderón. La lectura idealista del Calderón de los casos de honra frente a la lectura de un sector de los intelectuales liberales de la Restauración, con Galdós a la cabeza, que Joan Oleza sintetiza como «el ambivalente giro del discurso liberal: de la recusación de la honra calderoniana a la atracción de la vida como sueño $»^{22}$. Ese giro del discurso liberal guía el devenir de los acontecimientos en La Regenta: la historia de una señora mal casada, finalmente adúltera, para cuyo adulterio podemos encontrar todo tipo de justificaciones a lo largo de ventiocho de los treinta capítulos que componen la obra. Y para mayor deslegitimación del principio de la honra, su mayor defensor a lo largo de todo el libro lleva a cabo su recusación en el momento decisivo en que tiene que afrontar la deshonra real de su casa (cap. XXIX, p. 940), de igual forma que hiciera el viejo Carrizales y, más tarde, el filósofo práctico de Fortunata y Jacinta, don Evaristo González Feijoo. No quiero decir con esto que se lleve a cabo una crítica de Calderón. Creo que se trata de lo que podríamos llamar una crítica de segundo nivel dirigida, por una parte, contra la lectura idealista y, por otra, contra lo que Oleza ${ }^{23}$ llama «las refundiciones de dramas del siglo XVII» cuya realidad moral no tiene cabida en la España del XIX.

Llegamos así a un tercer punto de vista, el de Álvaro Mesía. Si antes he comentado que la libertad de expresión de los personajes de La Regenta se encuentra limitada por la elección del estilo indirecto y por las injerencias del narrador, en el caso de Mesía tal limitación es, además, libremente elegida. Si conocemos la opinión de don Álvaro acerca del drama de Zorrilla es porque el narrador omnisciente considera necesario que estemos al corriente. El drama le parece inmoral; sin embargo, considera verosímil y hasta ingeniosa la traición de don Juan a don Luis y la burla de doña Ana. Como don Víctor y Ana Ozores, tampoco Mesía mira el drama con perspectiva, distanciándose de su realidad individual, sino que se proyecta en él. La gran diferencia estriba en que don Álvaro no lo dice. Lo que sí dice, cuando es oportuno, es que es mucho mejor el Don Juan de Molière, aparentando un reconocimiento de la capitalidad cultural de París, como aparenta un sentimiento de acendrado patriotismo ante Quintanar alabando el drama de Zorrilla «con frases de gacetillero agradecido» o una pose romántica, muy del gusto de las señoras ${ }^{24}$, ante la Regenta. Porque la clave de la perspectiva de este personaje es la apariencia; que es, en definitiva, la clave de la moral burguesa. Fijémonos en el comentario que suscita el Don Juan de Zorrilla entre los asiduos al palco o bolsa de su adversario -no político, sino personal- Ronzal:

\footnotetext{
${ }^{21}$ Edición citada.

22 Oleza, Joan (2003): «Calderón y los liberales». En: Giornate calderoniane. Calderón 2000. A cura di Enrica Cancelliere. Palermo: Flaccovio Editore, pp. 395-418.

23 Idem

${ }^{24}$ El narrador compara aquí la pose de Mesía con la de los personajes de Feuillet. Respecto al éxito de este tipo de literatura entre las personas elegantes de su época escribe Emilia Pardo Bazán: «De diez veces, nueve era una novela francesa, género azucarado, Ohnet, Feuillet o Cherbuliez; casi nunca un libro místico o histórico; jamás una novela española...» La mujer española, tomado de Fuentes, V., nota 12 de p. 436 de su edición citada de $L a R e$ genta. El rechazo de la literatura escapista por parte de los escritores españoles englobados dentro del realismonaturalismo, manifestado en las alusiones que encontramos a lo largo de La Regenta, se hace patente en estas palabras de Pardo Bazán.
} 
- ¡Mire usted el pueblo! -dijo un concejal de la otra bolsa, volviéndose a Foja, el ex-alcalde liberal.

- ¿Qué tiene el pueblo?

- ¿Que es un majadero! Aplaude la gran felonía de arrancar la careta a un enmascarado...

- Que resulta padre -añadió Ronzal-; circunstancia agravante.

- El hombre abandonado a sus instintos es naturalmente inmoral, y como el pueblo no tiene educación...

(p. 536)

Es el propio Mesía quien, en su fuero interno, equipara vanagloria y honor (p. 525). Mesía, como Ana Ozores, contempla el mundo como un teatro, pero como un teatro de títeres donde su objetivo no es cortar los hilos sino manejarlos. Don Álvaro es, en este sentido, lo contrario a doña Ana, la inadaptada. Porque Mesía se ajusta perfectamente a la definición de los vetustenses que el narrador nos da al comienzo del capítulo: «Son anfibios que se preparan a vivir debajo del agua la temporada que su destino les condena a este elemento» (p. 507). Y a través de la perspectiva del jefe del Partido Liberal Dinástico de Vetusta, Clarín asesta el golpe de gracia al biperspectivismo de contradictorios que separa aparentemente, como no podía ser de otra manera, a la sociedad vetustense. La imagen de los anfibios y su relación con Mesía nos remiten al comienzo del capítulo VIII:

El marqués de Vegallana era en Vetusta el jefe del partido más reaccionario entre los dinásticos; pero no tenía afición a la política y más servía de adorno que de otra cosa. Tenía siempre un favorito que era el jefe verdadero. El favorito actual era (¡oh escándalo del juego natural de las instituciones y del turno pacífico!), ni más ni menos, don Álvaro Mesía, el jefe del partido liberal dinástico.

El significado de la metáfora resulta transparente a partir de esta caracterización de los dos partidos dinásticos tan reveladora, a su vez, -como señala Víctor Fuentes en nota al pie- de la opinión de Clarín sobre el «tinglado canovista». Esto es, las bases del sistema político bipartidista de Cánovas no son ideológicas y mucho menos morales, son los intereses económicos del grupo social dominante: la burguesía.

... don Álvaro cuidaba de los negocios conservadores lo mismo que de los liberales. [...] Así era el turno pacífico en Vetusta, a pesar de las apariencias de encarnizada discordia. (capítulo VIII)

No resulta difícil reconocer el materialismo histórico como base teórica de esta explicación:

La idea cardinal que inspira todo el Manifiesto, a saber: que el régimen económico de la producción y la estructuración social que de él se deriva necesariamente en cada época histórica constituye la base sobre la cual se asienta la historia política e intelectual de esa época, y que, por tanto, toda la historia de la sociedad -una vez disuelto el primitivo régimen de comunidad del suelo- es una historia de luchas de clases, de luchas entre clases explotadoras y explotadas, dominantes y dominadas, $[\ldots]{ }^{25}$

\footnotetext{
${ }^{25}$ Engels, Friedrich: «Prólogo a la edición alemana de 1883». En: Marx, Karl y Engels, Friedrich (1974): El manifiesto comunista. Notas de Riazanof. Madrid: Ayuso, p. 57.
} 
No es necesario salir del capítulo XVI para encontrar el paralelismo entre el jefe del Partido Liberal Dinástico de Vetusta y el del Partido Conservador de la España de la Restauración. Tal vez, incluso, resulte más interesante, desde el punto de vista de la teoría literaria, el fragmento correspondiente a este capítulo. Me refiero a la descripción cronotópica del teatro de Vetusta. Teniendo en cuenta el concepto de cronotopo definido por Bajtin $^{26}$, fijémonos en la precisión con la que el narrador describe la distribución espacial de los representantes de las fuerzas políticas de Vetusta en el hemiciclo de nuestro Coliseo de la plaza del Pan. El narrador nos informa de que el «palco de Vegallana era una platea contigua al proscenio», lugar privilegiado para escrutar al respetable sacrificando la perspectiva respecto al escenario, pues ya sabemos que «las personas decentes de palcos principales y plateas [...] no iban al teatro a ver la función, sino a mirarse y despellejarse de lejos» (p. 526). Además, en Vetusta las plateas quedan algo escondidas para salvaguarda de la discreción de estas personas decentes, de ahí su nombre de «bolsas». «La bolsa de enfrente -izquierda del actor-era la de Mesía y otros elegantes del casino»; es decir, la de la oposición. «Pepe Ronzal, alias Trabuco, [...] era el núcleo de la que se llamaba la otra bolsa». Nótese la disemia: por un lado, esta es la verdadera bolsa rival de la de Mesía, y por otro lado, en Vetusta no hay lugar para la unicidad, todo ha de tener repetición, otra bolsa, otro invierno. Y es en la unión de esa dualidad semántica donde encontramos el sentido de la existencia de la bolsa de Ronzal. Es la rivalidad la que lleva a los otros a imitar a los unos: si los unos son escépticos, los otros, cínicos, si seductores los unos, compradores de carne humana los otros, si los unos imitaban «costumbres, modales y gestos» de la capital, los otros exageraban las formas hasta llegar a lo grotesco - «Desde su bolsa se arrojaban perros chicos a la escena, para exagerar la falta de compostura de los de enfrente»- mientras alardeaban de que «en Vetusta no se admitían imposiciones de nadie». La bolsa de Ronzal aparece así como la imagen especular de la de Mesía; su reflejo es el propio de los espejos del callejón del Gato. De aquí al esperpento de Valle-Inclán, ¿hay un paso?

Si nos alejamos algo más para adquirir perspectiva, descubrimos que la descripción cronotópica sigue una trayectoria que comienza en el lado derecho del proscenio, en la bolsa de Vegallana, la de la aristocracia, continúa en el punto diametralmente opuesto, la bolsa de Mesía, la de la burguesía elegante, y regresa, describiendo un ángulo agudo, como el de un haz de luz reflejado, al lado derecho del proscenio, a la bolsa que toca con la de los Marqueses, la de Ronzal y la burguesía que podríamos llamar provinciana. Esta, a su vez, nos devuelve el reflejo deformado, aún más degradado, de la imagen de la burguesía. Mesía, por tanto, constituye el punto de confluencia de la aristocracia y la burguesía. Y esto, dentro de las coordenadas temporales de la España de la Restauración, nos remite, de nuevo, a Cánovas del Castillo.

\footnotetext{
${ }^{26}$ Bajtín define el cronotopo como «the intrinsic connectedness of temporal and spatial relationships that are artistically expressed in literature». La función de las unidades cronotópicas dentro del texto no es únicamente de carácter escénico, sino que, siguiendo la teoría de Bajtín, cumplen allí una función semántica en toda su extensión: «every entry into the sphere of meaning is accomplished only throug the gates of the chronotope». Esto es lo que diferencia las descripciones propias del realismo-naturalismo de las descripciones estáticas del costumbrismo. Y lo que hace posible que establezcamos esa analogía entre la realidad novelada y la realidad histórica, puesto que «all the novel's abstract elements - philosophical and social generalizations, ideas, analyses of cause and effect gravitate toward the chronotope and through it take on flesh and blood». Bajtin, M. (1981): «Forms of Time and the Chronotope in the Novel». En: The Dialogic Imagination. Austin: University of Texas Press. Las citas corresponden a las páginas 84,258 y 250 .
} 
De igual forma, el materialismo histórico gravita en torno a la descripción cronotópica del teatro:

En los tiempos históricos nos encontramos a la sociedad dividida casi por doquier en una serie de estamentos, dentro de cada uno de los cuales reina, a su vez, una nueva jerarquía social de grados y posiciones. [...]

La moderna sociedad burguesa que se alza sobre las ruinas de la sociedad feudal no ha abolido los antagonismos de clase. Lo que ha hecho ha sido crear nuevas clases, nuevas condiciones de opresión, nuevas modalidades de lucha, que han venido a sustituir a las antiguas. ${ }^{27}$

Esta idea es dramatizada mediante el cronotopo creado por Clarín:

Aunque el palco de los Marqueses tocaba con el de Ronzal, pocas veces los abonados del último se atrevían a entablar conversación con los Vegallana o quien allí estuviera convidado. Además de que el tabique intermedio dificultaba la conversación, los más no se atrevían, de hecho, a dar por no existente una diferencia de clases de que en teoría muchos se burlaban.

«Todos somos iguales - decían muchos burgueses de Vetusta- la nobleza ya no es nadie, ahora todo lo puede el dinero, el talento, el valor, etc., etc.»

Llegados a este punto, la analogía entre el aristocrático Mesía y el monárquico Cánovas resulta evidente:

En cambio los de la bolsa de don Álvaro saludaban a los Vegallana; sonreían a la marquesa, asestaban los gemelos a Edelmira y hacían señas al Marqués, y a Paco, que solían visitar aquel rincón comme il faut.

Y no sólo eso, sino que el retroceso de la burguesía ${ }^{28}$ y la revalorización de lo nobiliario llega a tal extremo que ni siquiera los despreciados por el grupo social aristocrático presentaban ningún tipo de oposición: «Ronzal se vengaba diciendo que la Marquesa era republicana».

¿Dónde queda, pues, la verdadera oposición dialéctica entre las fuerzas políticas y sociales de Vetusta o de la España de la Restauración? Para Ana, la lucha dialéctica generadora de su conflicto interior está polarizada entre don Álvaro y don Fermín, como para la burguesía vetustense las dos fuerzas sociales antagónicas están representadas por el jefe del Partido Liberal Dinástico y por el Magistral de la catedral. La rivalidad entre ambos es cierta. Cada uno en su ámbito, el casino y la catedral, respectivamente, es el verdadero autor de la comedia, el favorito del hombre que ostenta el cargo oficial, el marqués de Vegallana y el obispo de la diócesis. Ambos se disputan la conquista de Vetusta y de Ana Ozores. De igual forma que don Álvaro está al tanto del tinglado caciquil de Vetusta:

Si mandaban los del marqués, don Álvaro repartía estanquillos, comisiones y licencias de caza, y a menudo algo más suculento, como si fueran gobierno los suyos; pero cuan-

\footnotetext{
${ }^{27}$ Marx, Karl y Engels, Friedich (1974: 72-73)

${ }^{28}$ Fuentes, Víctor, Nota al pie $n^{\circ} 40$ del cap. XVI de la edición citada.
} 
do venían los liberales, el marqués de Vegallana seguía siendo árbitro en las elecciones, gracias a Mesía, y daba estanquillos, empleos y hasta prebendas. (cap. VIII, p.257)

\section{El Magistral}

... conocía una especie de Vetusta subterránea: era la ciudad oculta de las conciencias. [...] A más de un liberal de los que renegaban de la confesión auricular, hubiera podido decirle las veces que se había embriagado, el dinero que había perdido al juego, o si tenía las manos sucias o si maltrataba a su mujer, con otros secretos más íntimos. (cap. XI, pp. 347-348)

Es decir, ambos tenían la capacidad de promover «el escándalo» y con él la perdición de cualquier vetustense. En esto se fundamentaba su poder sobre la ciudad. Cada uno en su teatro: el de los negocios era patrimonio del «materialista elegante» (p. 522) y el de las conciencias le corresponde al clérigo versallesco.

Lo que enfrenta a los dos rivales no es, como cree Ana, una discrepancia en el orden moral, sino su deseo erótico y su deseo de poder. El narrador se encarga de presentarlos como dos estrategas de la conquista: «la Regenta tenía la cabeza a pájaros, y no había que aventurar ni un mal pisotón, so pena de exponerse a echarlo a rodar todo» (p. 514), piensa don Álvaro; «procuraba despertar con gran prudencia [los procesos de la piedad], temeroso de perder en un día todo el terreno adelantado, si daba un mal paso» (p. 515) dice el narrador de don Fermín. Son contrarios, sí, pero no contradictorios: «uno diablo y otro santo» (p. 549), «pero el Diablo cuando era Luzbel todavía; el Diablo Arcángel también;» (cap. XIII, p. 446). Puesto que para Ana, Mesía encarna la caída subversiva, liberadora, que creerá vivir en el capítulo XXXVIII: «Aquello era caer, sí, pero caer al cielo» (p. 885). Sin embargo, el don Juan vetustense nada tiene que ver con don Félix de Montemar; el don Juan que, como Luzbel, desafía al mismo Dios:

Ni vio el fantasma entre sueños

del que mató en desafío,

ni turbó jamás su brío

recelosa previsión.

(El estudiante de Salamanca, parte primera, vv. 112-119)

-Siento me enamora más vuestro despego,

y si Dios se enoja, pardiez que hará mal:

véame en vuestros brazos y máteme luego.

-¡Vuestra última hora quizá esta será!...

(El estudiante de Salamanca, parte cuarta, vv. 224-230 $)^{29}$

El narrador despoja al don Juan previsor de vetusta de la valentía que ennoblece al estudiante de Salamanca y al burlador de Sevilla. Y lo hace, muy hábilmente, mostrando su naturaleza cobarde como una flaqueza que el propio Mesía se esfuerza en negarse

\footnotetext{
${ }^{29}$ Espronceda, José de (1840): El estudiante de Salamanca. Edición digital de la Biblioteca Virtual Miguel de Cervantes a partir de la edición de Poesías de don José Espronceda, Madrid, Imp. Yepes, 1840, cotejada con la edición crítica de Benito Varela Jácome (1979). Madrid: Cátedra.
} 
a sí mismo. Por ese motivo aparece «entre los primeros disparates del ensueño» (pp. 546-547):

vio de repente, y ya casi dormido, la figura bonachona de don Víctor. Pero le vio entre los primeros disparates del ensueño, vestido de toga y birrete, con una espada en la mano.

Relacionando así el significado premonitorio de los miedos de Mesía con el «supersticioso miedo» (p. 544) de la Regenta al descubrir el sentido del cuarto acto del Don Juan de Zorrilla. Clarín adopta aquí la solución de Lope en El caballero de Olmedo, pero adaptándola al pensamiento de sus lectores y de sus personajes:

¿Qué poco crédito dí

a los avisos del cielo!

Valor propio me ha engañado ${ }^{30}$,

y muerto envidias y celos.

(vv. 2462-2465) ${ }^{31}$

La católica doña Ana que «creía que Dios le daba de cuando en cuando avisos, le presentaba coincidencias para que ella aprovechase ocasiones» (p. 529), coincide en su error con el caballero del XVII al interpretar que su miedo tiene un origen supersticioso; porque, como don Alonso en Olmedo, la Regenta es la más virtuosa y la más piadosa dama de Vetusta. Y su mecanismo de represión legitima la concepción supravetustense y suprahumana que tiene de sí misma: «Anita no recordaba haber soñado aquella noche con don Álvaro» (p. 547). Mesía, el representante de la modernidad burguesa, no puede fundamentar en escrúpulos religiosos la negación del significado premonitorio de sus ensueños; para el «materialista elegante» no son más que «disparates».

Vemos cómo en La Regenta la poesía, la literatura y los sueños forman parte de la realidad. Así lo demuestra la perfecta incrustación del drama de Zorrilla en este fragmento de la vida de nuestros personajes. A través de la vivencia autorreferencial ${ }^{32}$ de Ana Ozores la literatura se convierte en historia, y así el teatro de Vetusta encierra para ella dos realidades. Porque Ana no está siendo espectadora del drama, sino del reflejo de su propio conflicto interior. Por eso el narrador nos dice: «El altercado de don Juan y el Comendador hizo a la Regenta volver a la realidad del drama» (p. 544). A partir de aquí la obra de Zorrilla adquiere un sentido premonitorio del final de la novela, que infunde miedo en la Regenta.

Ana, muy oportunamente, abandona el teatro al terminar la primera parte de la obra. Quizá su marcha esté relacionada con la opinión de Clarín acerca de la segunda parte, donde «es mucho más lo malo que lo bueno.» ${ }^{33}$ Pero no deja de ser conveniente para que

\footnotetext{
${ }^{30}$ Para Antonio Rey Hazas, en este verso don Alonso reconoce su pecado de soberbia. Y esta es la falla que Lope introduce en la figura intachable del caballero para lograr que su muerte sea poéticamente justa. «Algunas Precisiones sobre la interpretación de El caballero de Olmedo». En: Edad de Oro V, Madrid: Universidad Autónoma de Madrid, 1986, pp. 183-202.

${ }^{31}$ Lope de Vega y Carpio, Félix (1983): El caballero de Olmedo. Joseph Pérez (ed.). Madrid: Castalia.

${ }^{32}$ López Aranguren, José Luis (1976): «De La Regenta a Ana Ozores». En: Estudios Literarios. Madrid: Gredos, p. 182.

33 Alas, Leopoldo: «El teatro de Zorrilla». En: Palique. Edición digital de la Biblioteca Virtual Miguel de Cervantes.
} 
la Regenta mantenga la identificación establecida entre ese don Juan salvador de doña Inés y don Álvaro Mesía. Si Ana presenciase la segunda parte del drama, puede que encontrase a Mesía más parecido a Mejía, el burlador de mujeres que no se enamora; y que descubriera en doña Ana Ozores de Quintanar no solo rasgos de doña Inés de Ulloa, sino también de doña Ana de Pantoja, la mujer que no enamora a don Juan, como parece sugerir Don Víctor mediante un error tan oportuno como los fragmentos de comedias con los que nos deleita: «le parecía indigna de un caballero la aventura de don Juan con doña Inés de Pantoja» (p. 524).

Si a este error en la identificación de los personajes del drama le sumamos la consideración del adulterio por parte de la burguesía «distinguida» (p. 533)-«creían que un hombre de mundo no puede vivir sin querida, y todos la tenían, más o menos barata;» (p. 533) - el que sus más allegados, Visita, Paquito Vegallana y hasta «el bendito don Víctor [...] sin querer» (p. 511) propicien la conquista de Mesía y el hecho de que lo que Vetusta condena, como señala Aranguren, «no es, de ningún modo, la conducta en sí -peor era o había sido la de Obdulia, Visita, los miembros de la familia Vegallana- sino el «escándalo» de no haber sabido guardar «las apariencias», ${ }^{34}$ ¿quien frena a Ana para vivir el que imagina amor verdadero y liberar su erotismo y sensualidad reprimidos? El Magistral. «Ana nerviosa, vio aparecer a don Álvaro [...]; y fue un motín general del alma, que hubiera asustado al Magistral de haberlo visto, lo que la Regenta sintió con deleite dentro de sí» (p. 522). No menciona siquiera a don Víctor, el marido deshonrado. Si miramos la obra como un caso de honra, la función dramática de defensor se desplaza del marido a uno de los galanes que pretenden a la dama. Tal desplazamiento lo encontramos también en El caballero de Olmedo, donde don Rodrigo, el galán rival, asume la función dramática de defensor del honor y de la honra de la casa de don Pedro. Aunque no sea esa, como ocurre en La Regenta, sino los celos, la verdadera motivación de don Rodrigo y del Magistral.

La lucha dialéctica que vive la Regenta no es extrapolable, sin embargo, al plano colectivo. Son las mismas «personas decentes», haciendo gala de su naturaleza anfíbica, las que acuden al teatro para no ver la representación y las que envían a sus muertos «aquella especie de besa-la-mano» (p. 510) el día de Todos los Santos. Los mismos «carlistas y liberales que llenaban el crucero» (cap. XXIII, p. 746) en la misa del Gallo y los mismos que se dan cita en el casino para contemplar el espectáculo de la humillación de la Regenta en la procesión del Viernes Santo (cap. XXVI). Porque en Vetusta no hay un sentimiento religioso verdadero, como tampoco el ateísmo es verdadero. Comparemos si no la conversión de don Pompeyo Guimarán con los preparativos premortem de don Evaristo Feijoo en Fortunata y Jacinta. Y, sobre todo, recordemos el significado que tiene para de Pas dicha conversión: «¡Oh! ¡qué gran efecto teatral...!» (cap. XXVI, p. 81) El de don Pompeyo, como el de Mesía, es un «anticlericalismo elemental» ${ }^{35}$, propio de una burguesía que se ha apropiado del adjetivo liberal, cuya máxima parece coincidir con la célebre frase del príncipe don Fabrizio de El Gatopardo: «Es necesario que todo cambie para que todo permanezca igual».

Para encontrar el verdadero motor del cambio social habrá que ampliar la perspectiva, antes descrita, del hemiciclo vetustense y mirar con Ana Ozores al escenario y al pa-

\footnotetext{
34 López Aranguren, José Luis (1976: 204)

${ }^{35}$ Rodríguez Puértolas (1984: 170)
} 
raíso. Paradójicamente, es sobre el escenario donde encontramos la verdadera oposición a la apariencia vacua del gran teatro de Vetusta: «el realismo poético» (p. 539) de la vida, para nosotros ficticia, de la González. Y es la defensa de esa realidad poética y, probablemente, la intención de Clarín de rendir un homenaje ${ }^{36}$ al Don Juan Tenorio de Zorrilla, las que justifican la catarsis de Ana Ozores: «sintiendo por aquella Inés una compasión infinita» (p. 544). Ana «admiraba no menos el desdén con que se veía y oía todo aquello desde palcos y butacas; aquella noche el paraíso, alegre, entusiasmado, le parecía mucho más inteligente y culto que el señorío vetustense» (p. 538). Esto es, la «generación nueva» de «los obreros» (cap. XX, p. 644):

... la generación nueva no era clerófoba más que a ratos; era amiga de la taberna, no del club. Se hablaba sólo de revolución social; y ya se decía que los curas no son ni más ni menos malos que los demás burgueses. Malo era el fanatismo, pero el capital era peor.

En definitiva, el biperspectivismo de contradictorios enunciado en el refrán vetustense, «O el cielo o el suelo» (p. 507), queda disuelto cuando contemplamos, desde la distancia interpuesta por la voz narradora, esa Vetusta que «se distinguía por su acendrado patriotismo, su religiosidad y su afición a los juegos prohibidos» (cap. VI, p. 223). Y es desde la propia lógica interna de su estructura sociomoral, desde la lógica interna del relato, desde donde emerge esa realidad teatral del absurdo. Esta es, desde mi punto de vista, la base del realismo crítico de Clarín.

\section{A modo de conclusión}

Clarín muestra al lector la realidad en perspectiva, pero sin perder de vista la individualidad de sus personajes: el movimiento narrativo de vaivén, con el que pasamos de lo colectivo a lo individual, en una especie de ciclo retroalimentativo solidario, por un lado, con el movimiento circular de los acontecimientos a lo largo del tiempo; y por otro, con la dialéctica de contradictorios y contrarios que rige la lógica interna del relato ( $\ll \mathrm{O}$ el cielo o el suelo», o conservadores o liberales, o don Fermín o don Álvaro, o misticismo o erotismo) cuya dicotomía alcanza el más hondo patetismo cuando la elección es concebida en términos de «o el individuo o la sociedad». Esta es la tragedia de Ana Ozores. Y así es la simplicidad biperspectivística de esa estructura sociomoral monocorde, cuya lógica absurda es puesta de manifiesto a través de un recurso tan cervantino como la polifonía narrativa. Si bien esa polifonía nos llega a través del estilo indirecto, aunque libre, en el que el narrador condiciona la lectura de igual forma que «el régimen económico de la producción y la estructuración social que de él se deriva necesariamente en cada época histórica» ${ }^{37}$ condicionan las vivencias y la vida de los individuos.

\footnotetext{
${ }^{36}$ Para Clarín, «El Trovador y Don Juan Tenorio son los mejores dramas de todos los españoles del siglo XIX. [...] Don Juan y Doña Inés no son románticos...son clásicos, del clasicismo perdurable.» Alas, Leopoldo: «El teatro de Zorrilla». En: Palique. Edición digital de la Biblioteca Virtual Miguel de Cervantes.

${ }^{37}$ Engels, Friedrich, ob. cit.
} 


\section{BIBLIOGRAFÍA}

Alarcos, E. (1979): «La estructura de La Regenta». En: Rico, F. (coord.), Historia y crítica de la literatura española, vol. V. Barcelona: Crítica.

Alas, Leopoldo (1999): La Regenta. Ed. Víctor Fuentes. Madrid: Akal.

Alas, Leopoldo: «El teatro de Zorrilla». En: Palique. Edición digital de la Biblioteca Virtual Miguel de Cervantes.

Bajtín, Mijaíl: (1981): «Forms of Time and the Chronotope in the Novel». En: The dialogic Imagination. Austin: University of Texas Press.

Bousoño, C. (1970): Teoría de la expresión poética. Madrid: Gredos.

Calderón de la Barca, Pedro (1981): La vida es sueño. Ed. José María Valverde. Barcelona: Planeta.

Cervantes y Saavedra, Miguel de (1994): El ingenioso hidalgo don Quijote de la mancha. Ed. Florencio Sevilla Arroyo y Antonio Rey Hazas. Alcalá de Henares: Centro de Estudios Cervantinos.

Espronceda, José de (1840): El estudiante de Salamanca. Edición digital de la Biblioteca Virtual Miguel de Cervantes a partir de la edición de Poesías de don José Espronceda, Madrid, Imp. Yepes, 1840, cotejada con la edición crítica de Benito Varela Jácome (1979). Madrid: Cátedra.

Fuentes, Víctor (1999): «Clarín y la novela de la modernidad naturalista». En: «Estudio preliminar» a su edición de La Regenta.

Lope de Vega, Félix (1983): El caballero de Olmedo. Ed. Joseph Pérez. Madrid: Castalia.

López Aranguren, J. Luis (1976): «De La Regenta a Ana Ozores». En: Estudios Literarios. Madrid: Gredos.

Martínez, J. A. (2001): «El punto de vista y las visiones esperpénticas en La Regenta». En: Actas del simposio sobre la obra de Clarín. Praga: Instituto de Estudios Románicos, Universidad Carolina de Praga.

Marx, Karl y Engels, Friedrich (1974): El manifiesto comunista. Madrid: Ayuso.

Oleza, Joan (2003): «Calderón y los liberales». En: Giornate calderoniane. Calderón 2000. A cura di Enrica Cancelliere. Palermo: Flaccovio Editore.

Pérez Galdós, B. (1901): «Prólogo» a la La Regenta. Edición digital de la Biblioteca Virtual Miguel de Cervantes.

Rey Hazas. Antonio (1986): «Algunas Precisiones sobre la interpretación de El caballero de Olmedo». En: Edad de Oro V. Madrid: Universidad Autónoma de Madrid.

Rodríguez Puértolas, Julio (coord.) (1984): Historia social de la literatura española II. Madrid: Castalia.

Sobejano, Gonzalo (1985): «La inadaptada (La Regenta, cap. XVI) ». En: El comentario de textos 1. Madrid: Castalia.

Tacca, Óscar (2000): Las voces de la novela. Madrid: Gredos. 


\section{VELIKO GLEDALIŠČE VETUSTA}

Članek predstavi branje 16. poglavja romana La Regenta skozi koncept kritičnega realizma. Avtorica meni, da Clarínu uspe s takšno konceptualizacijo literarnega ustvariti zgodovinsko perspektivo, ki je nujno potrebna za študijo resničnosti, v kateri so živeli on in njegovi sodobniki. $Z$ vidika semantike in strukture je zato zelo pomemben narativni postopek, ki bi ga lahko imenovali prehajanje med notranjostjo in zunanjostjo oseb. Takšno gibanje sem in tja, kakor urino nihalo, podpira dialektični boj, v katerem je Ana Ozores včasih protagonistka, včasih pa je izničena in se spremeni v bojno polje. Clarín skozi kronotopski opis družbenih sil v Vetusti razkriva zgolj navidezno protislovne odnose, ki vladajo med njimi. Iz te notranje logike družbenomoralne strukture Vetuste vznikne gledališka resničnost absurda. 